\title{
The small molecule ZY-214-4 may reduce the virulence of Staphylococcus aureus by inhibiting pigment production
}

Jingyi Yu', Lulin Rao', Lingling Zhan ${ }^{1}$, Bingjie Wang ${ }^{2}$, Qing Zhan ${ }^{3}$, Yanlei Xu ${ }^{3}$, Huilin Zhao ${ }^{2}$, Xinyi Wang ${ }^{2}$,

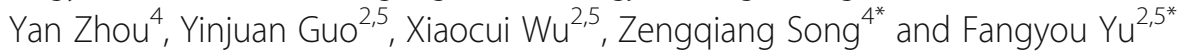

\begin{abstract}
Background: In recent years, clinical Staphylococcus aureus isolates have become highly resistant to antibiotics, which has raised concerns about the ability to control infections by these organisms. The aim of this study was to clarify the effect of a new small molecule, $\mathrm{ZY}-214-4\left(\mathrm{C}_{19} \mathrm{H}_{11} \mathrm{BrNO}_{4}\right)$, on S. aureus pigment production.

Results: At the concentration of $4 \mu \mathrm{g} / \mathrm{mL}, \mathrm{ZY}-214-4$ exerted a significant inhibitory effect on S. aureus pigment synthesis, without affecting its growth or inducing a toxic effect on the silkworm. An oxidant sensitivity test and a whole-blood killing test indicated that the S. aureus survival rate decreased significantly with ZY-214-4 treatment. Additionally, ZY-214-4 administration significantly reduced the expression of a pigment synthesis-related gene ( $r$ rtM) and the superoxide dismutase genes (sodA) as determined by real-time quantitative polymerase chain reaction (RT-qPCR) analysis. ZY-214-4 treatment also improved the survival rate of S. aureus-infected silkworm larvae.
\end{abstract}

Conclusions: The small molecule ZY-214-4 has potential for the prevention of S. aureus infections by reducing the virulence associated with this bacterium.

Keywords: Staphylococcus aureus, Pigment, crtM, Sod, Oxidation

\section{Background}

The skin and nasopharynx of approximately 20 to $30 \%$ of the world's population $[1,2]$ are continuously colonized by the Staphylococcus aureus. This bacterium is an opportunistic pathogen that can cause superficial skin diseases and numerous fatal diseases such as bacteremia and infective endocarditis, and also causing osteoarticular, pleuropulmonary, and device-related infections [36]. Vancomycin, a glycopeptide antibiotic that can inhibit cell wall biosynthesis, is the first-choice treatment for methicillin-resistant S. aureus (MRSA) infections [7,

\footnotetext{
* Correspondence: songzengqiang09@163.com; wzjxyfy@163.com ${ }^{4}$ School of Pharmaceutical Sciences, Wenzhou Medical University, Wenzhou 325000, China

2Department of Clinical Laboratory, Shanghai Pulmonary Hospital, Tongji University School of Medicine, Shanghai 200082, China

Full list of author information is available at the end of the article
}

8]; however, moderate or complete resistance to this antibiotic has become widespread among $S$. aureus strains $[8,9]$. Importantly, although significantly fewer antibiotics have been identified or synthesized this century compared with the last century [10], the prescription of antibiotics for the treatment of infections over the years has led to the emergence of drug-resistant $S$. aureus strains [11]. Eliminating bacterial virulence factors is increasingly used as a means of combating antibiotic resistance [12], and represents a strategy that avoids the emergence of drug resistance induced by bacterial stress $[12,13]$.

Notably, the success of $S$. aureus as a pathogen also lies in its ability to reduce oxidative stress [14]. Superoxide dismutase (SOD) is a key detoxifying enzyme [14$16]$ that converts reactive oxygen species (ROS) into less

C C The Author(s). 2021 Open Access This article is licensed under a Creative Commons Attribution 4.0 International License, which permits use, sharing, adaptation, distribution and reproduction in any medium or format, as long as you give appropriate credit to the original author(s) and the source, provide a link to the Creative Commons licence, and indicate if changes were made. The images or other third party material in this article are included in the article's Creative Commons licence, unless indicated otherwise in a credit line to the material. If material is not included in the article's Creative Commons licence and your intended use is not permitted by statutory regulation or exceeds the permitted use, you will need to obtain permission directly from the copyright holder. To view a copy of this licence, visit http://creativecommons.org/licenses/by/4.0/ The Creative Commons Public Domain Dedication waiver (http://creativecommons.org/publicdomain/zero/1.0/) applies to the data made available in this article, unless otherwise stated in a credit line to the data. 
harmful products, thereby allowing bacteria that infect the body to escape the body's immune system and survive $[12,14]$. Pigments produced by pathogenic microbes are known to be important virulence factors [17]. S. aureus defective in pigment production exhibit reduced infectivity and increased vulnerability to neutrophils [18], and cannot infect the mice in the mouse model $[3,19]$. For example, S. aureus mutants with defective carotenoid biosynthesis are more likely to be killed by oxidants, show impaired neutrophil survival and lower pathogenicity [20]. Pigment biosynthesis is mediated by proteins encoded by a five-gene cluster ( $c r t M, \operatorname{crt} N, \operatorname{crtP}, \operatorname{crt} \mathrm{Q}$, and $c r t O$ ) [21], which represents a potential new target for antibacterial therapy.

ZY-214-4, molecular formula $\mathrm{C}_{19} \mathrm{H}_{10} \mathrm{BrNO}_{4}$, contains a chromone ring and an $\mathrm{N}$-phenyl-substituted maleimide. Chromone and its derivatives are widely distributed in naturally occurring products and pharmaceuticals as key scaffolds, and chromone derivatives have been shown to exert antimicrobial activities against Penicillium spp., Escherichia coli, and Shigella flexneri [22-24]. Maleimide motifs are prevalent in many natural products and drug candidates, and possess a broad spectrum of biological properties, including antitumor and antibacterial activities [25-27]. However, no studies have reported on the antibacterial activity of chromone-maleimide hybrids in inhibiting golden pigment production in S. aureus. In this study, we sought to clarify whether subinhibitory concentrations of ZY214-4 can inhibit pigment production in clinical S. aureus strains.

\section{Results}

The effect of subinhibitory concentrations of ZY-214-4 on the growth of $S$. aureus strains

The minimum inhibitory concentration (MIC) of ZY214-4 was $64 \mu \mathrm{g} / \mathrm{mL}$ against $S$. aureus strains SA21,
SA882, and SA923, and $256 \mu \mathrm{g} / \mathrm{mL}$ against strains SA2698 and SA2956. To verify whether ZY-214-4 reduced the virulence of $S$. aureus by reducing the expression of virulence genes rather than the number of $S$. aureus cells, we generated a growth curve for these clinical isolates of $S$. aureus at a series of subinhibitory concentration (Additional Figure 1). We found that the number of bacteria in the late logarithmic growth period remained constant at the subinhibitory concentration of $4 \mu \mathrm{g} / \mathrm{mL}$ of ZY-214-4 (Fig. 1). Therefore, this concentration was used for subsequent experiments.

\section{ZY-214-4 inhibited pigment production}

We undertook a quantitative and qualitative assessment of pigment synthesis in ZY-214-4-treated and untreated cells. ZY-214-4 treatment markedly inhibited golden pigment production. Compared with the golden pigmentation of untreated $S$. aureus, that of $S$. aureus treated with ZY-214-4 was white or light yellow (Fig. 2a). Quantitative analysis showed that pigment production was decreased by $38.7-41.8 \%, 36.8-38.9 \%, 39.0-43.8 \%, 41.1-$ $42.8 \%, 54.1-56.7 \%$ in five ZY-214-4-treated clinical $S$. aureus isolates when compared with their respective untreated counterparts (Fig. 2b).

\section{The effect of $Z Y-214-4$ on the susceptibly of $S$. aureus to human blood and $\mathrm{H}_{2} \mathrm{O}_{2}$}

As ZY-214-4 could inhibit pigment production in S. aureus, and because the pigment can shield $S$. aureus cells from host oxidants, we next compared the sensitivity of ZY-214-4-treated $(4 \mu \mathrm{g} / \mathrm{mL})$ and untreated $S$. aureus to $\mathrm{H}_{2} \mathrm{O}_{2}$ and healthy human blood. The results of an $\mathrm{H}_{2} \mathrm{O}_{2}$ sensitivity assay showed that ZY-214-4-treated cells were substantially more sensitive to $\mathrm{H}_{2} \mathrm{O}_{2}$ than untreated control cells (Fig. 3a). Moreover, compared with untreated controls, both the number of colonies and the survival rate of clinical $S$. aureus strains were greatly decreased

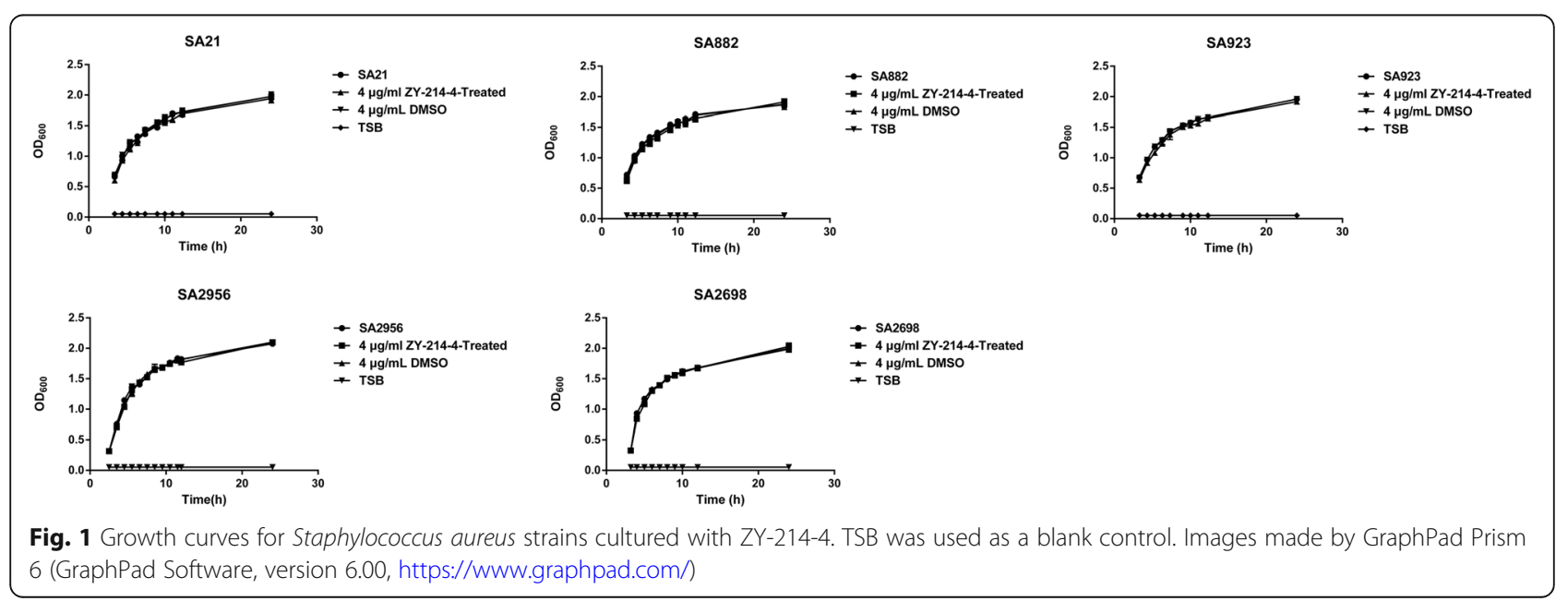




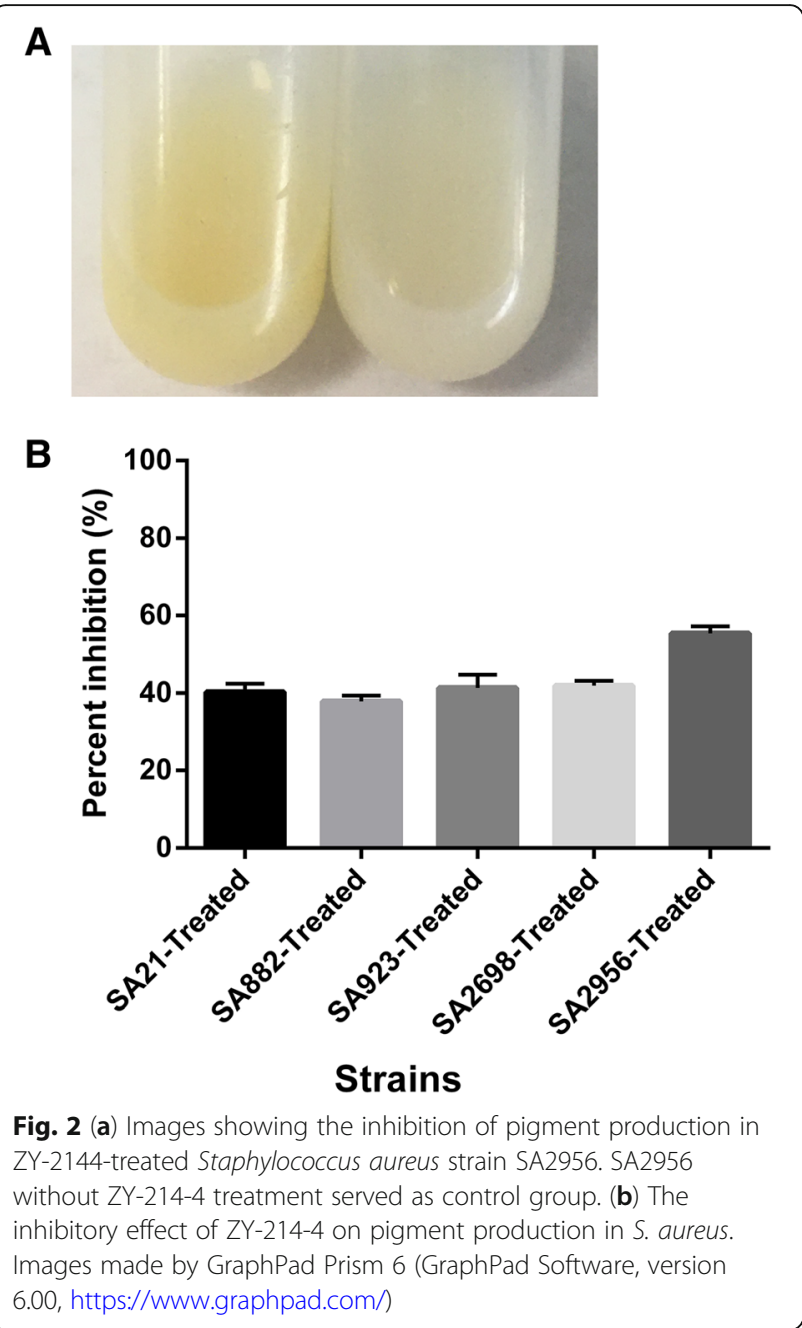

in the whole blood of healthy volunteers following ZY214-4 treatment (Fig. 3b). Together, these results indicated that $\mathrm{ZY}-214-4$ treatment reduced the resistance of S. aureus to human blood and $\mathrm{H}_{2} \mathrm{O}_{2}$.

Treatment with subinhibitory concentrations of ZY-214-4 downregulated the expression of the sod and crtM genes of S. aureus

We observed that pigment synthesis was reduced in $S$. aureus and that the bacterium was more sensitive to $\mathrm{H}_{2} \mathrm{O}_{2}$ and healthy blood following ZY-214-4 treatment. To further explore the mechanism underlying these effects of ZY-214-4 on S. aureus, we used RT-qPCR to measure the expression levels of $c r t M$, which is involved in antioxidant pigment synthesis, and that of $\operatorname{sod} A$ and $\operatorname{sod} M$, which are coding for superoxide dismutase, the enzymes that scavenge oxygen free radicals and play a key role in the evasion of host defenses. We found that the expression of $\operatorname{crtM}$ and $\operatorname{sod} A$ were down-regulated in ZY-214-4-treated S. aureus cells when compared with that in controls, and 3 out 5 strains were significant for reduction in expression of sodM. (Fig. 4).

\section{Analysis of the cytotoxicity of ZY-214-4}

To evaluate the cytotoxicity of ZY-214-4, we injected silkworms with different concentrations of ZY-214-4 (2$8 \mu \mathrm{g} / \mathrm{mL}$ ) and evaluated the effects after $24 \mathrm{~h}$. No deaths were observed in either the treatment or corresponding concentration of DMSO control group (Data not shown).

\section{ZY-214-4 reduced the virulence of $S$. aureus in infected silkworms}

We found that, in vivo, the virulence of $S$. aureus was significantly lower with ZY-214-4 treatment $(4 \mu \mathrm{g} / \mathrm{mL})$ than without. As shown in Fig. 5, following S. aureus infection, mortality occurred later in ZY-214-4-treated silkworm larvae than in untreated animals. After $5 \mathrm{~h}$, the mortality rate of untreated silkworm larvae was $100 \%$ for those infected with the S. aureus SA21 strain, 100\% for those infected with the SA882 strain, $90 \%$ for those infected with the SA923 strain, 90\% for those infected with the SA2698 strain, 100\% for those infected with the SA2956 strain. The respective values for ZY-214-4treated silkworm larvae were 50, 20, 10, 30, and $30 \%$. These results indicated that ZY-214-4 treatment can delay death in S. aureus-infected insects.

\section{Discussion}

Multidrug-resistant strains of $S$. aureus are a leading cause of skin and soft tissue infection [28, 29]. The ability of $S$. aureus to survive under diverse environmental pressures is an important determinant of its pathogenicity [21,30], highlighting the need for the development of alternative treatments. Many studies have shown that the $S$. aureus pigment is a key factor in its virulence [18, $31,32]$. The biosynthetic pathway of pigment is disrupted in a "deleted" crtM of S. aureus, resulting in the absence of pigmentation and enhanced susceptibility to killing by ROS [18]. One study reported that, in a mouse subcutaneous abscess model, $S$. aureus mutants with impaired carotenoid biosynthesis were more easily killed by oxidants and neutrophils and exhibited lower pathogenicity when compared with their wild-type counterparts [18].

In this study, we synthesized a new small-molecule compound-ZY-214-4-and selected five clinical S. aureus strains isolated from different sites of infection to investigate the effect of subinhibitory concentrations of ZY-214-4 on the virulence of this bacterium. Because we found that high concentrations of ZY-214-4 could inhibit $S$. aureus growth (Additional Figure 1), we selected a subinhibitory concentration $(4 \mu \mathrm{g} / \mathrm{mL})$ that did not affect the growth of the bacterium, thus excluding 

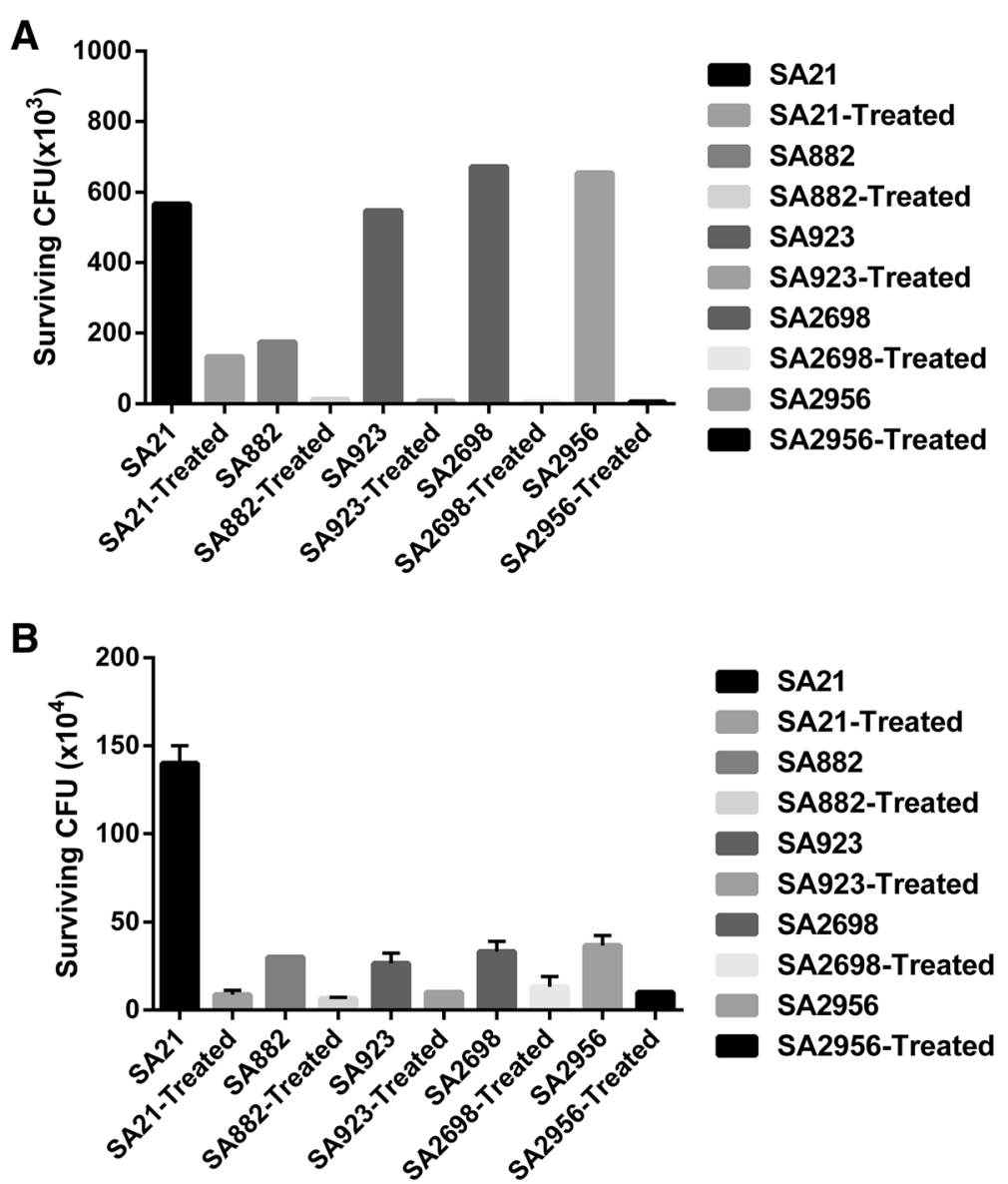

Fig. 3 The effect of ZY-214-4 (4 $\mathrm{gg} / \mathrm{mL})$ treatment on the survival of Staphylococcus aureus in $(\mathbf{a}) \mathrm{H}_{2} \mathrm{O}_{2}$ and (b) healthy human blood. Error bars indicate the SD and asterisks indicate statistical significance $(p<0.05)$. Images made by GraphPad Prism 6 (GraphPad Software, version 6.00, https://www.graphpad.com/)

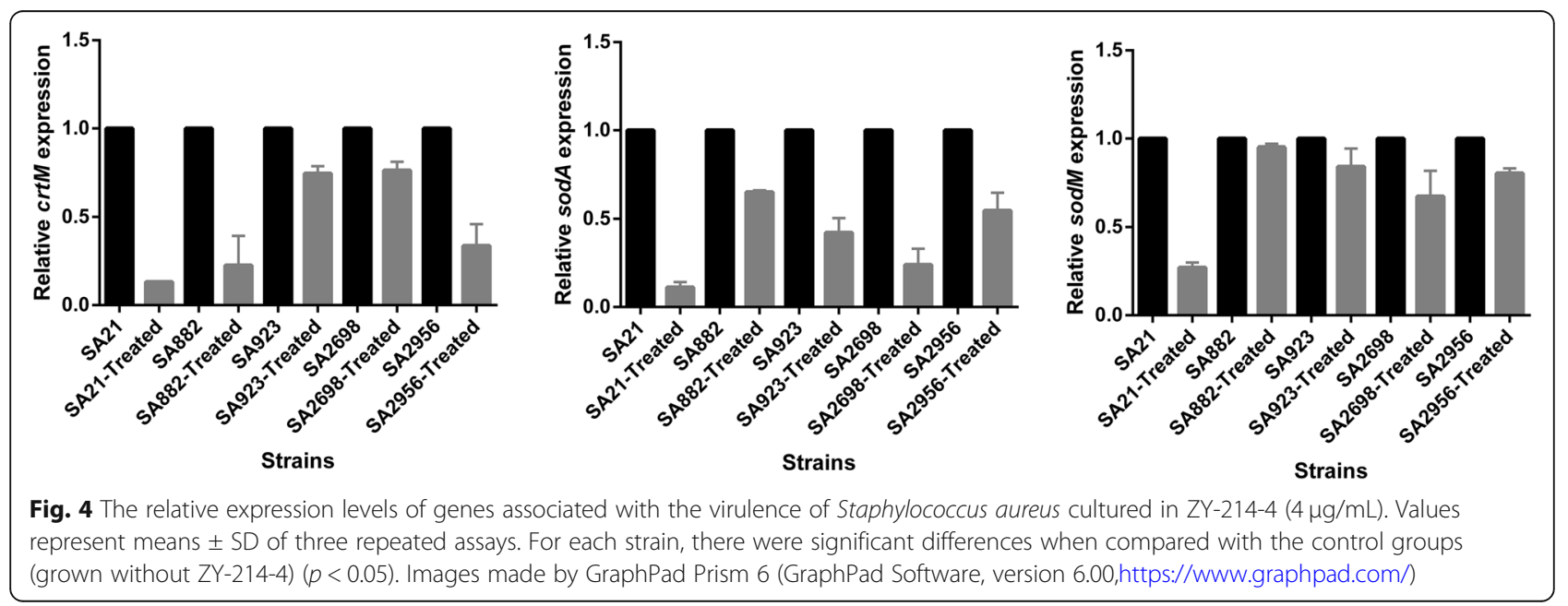




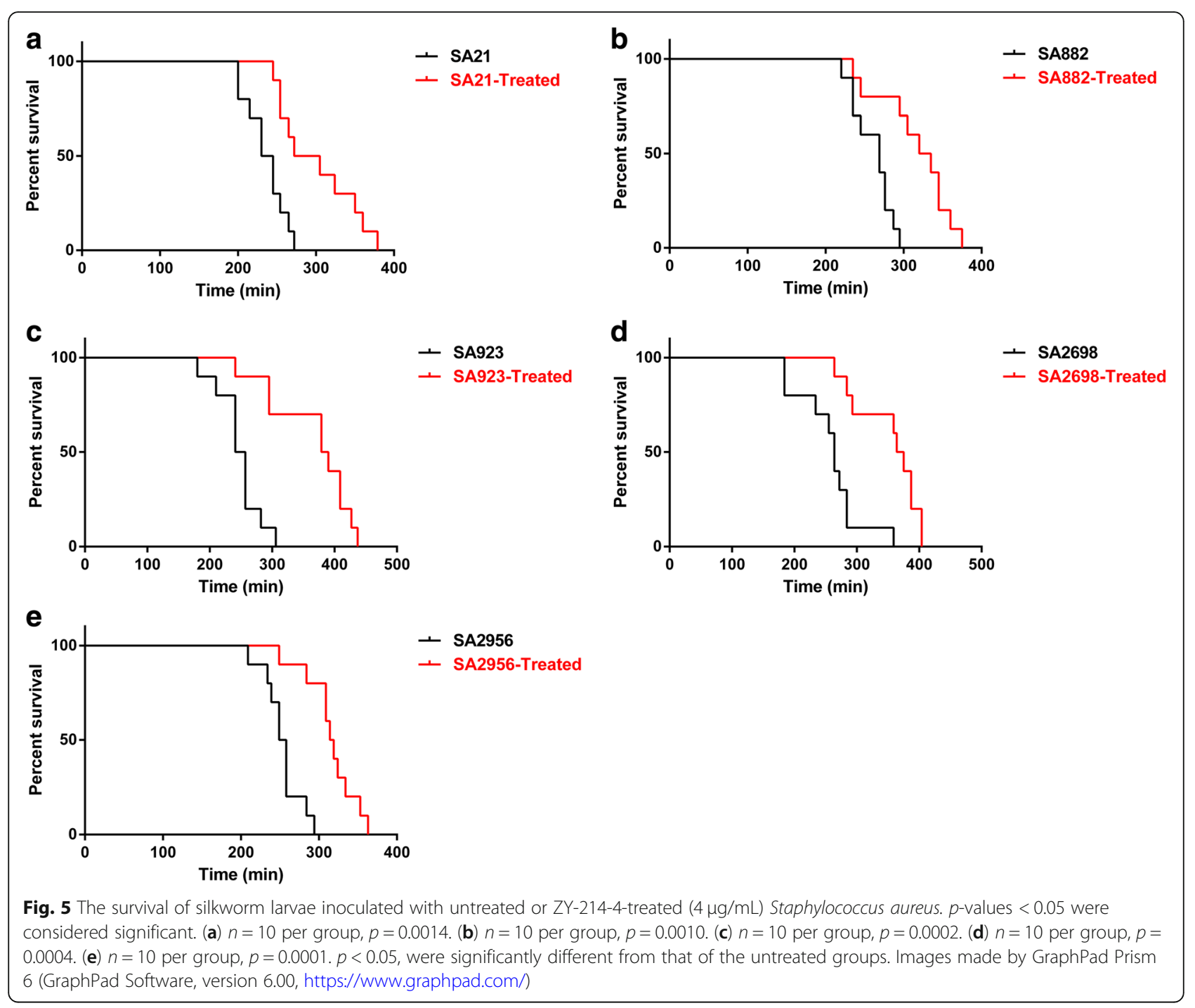

the possibility that any reduction in virulence could result from a reduction in the number of bacteria.

The pigment of $S$. aureus has been reported to be an important virulence factor [33]. The pigment has antioxidant properties, and its many double bonds can react with ROS produced by neutrophils and macrophages, thereby protecting S. aureus against oxidative stress [34]. The first key step in pigment biosynthesis is catalyzed by dehydrosqualene synthase (also known as diphosphonene synthase or CrtM) [35]. Many related studies have found that there is a positive correlation between pigment production and $c r t M$ expression [35, 36]. Here, we found that pigment production and $\operatorname{crtM}$ gene expression were significantly downregulated in $S$. aureus under the effect of ZY-214-4. We speculate that ZY-214-4 exerts its inhibitory effect on pigment production by reducing the expression of $c r t M$.

To deal with ROS, bacteria have evolved complex oxidative stress response mechanisms [37]. Notably, $S$. aureus has developed several means of escaping the immune systems of its hosts [38, 39], including phagocytemediated oxidative killing $[40,41]$. This resistance is mediated by SOD production [42-44]. The absence of $\operatorname{sod} A$ can reduce $S$. aureus virulence in a model of abscess or retroorbital infection $[45,46]$. SodM is as important as SodA [16]. SOD is a representative antioxidant enzyme that can eliminate ROS produced under oxidative stress. SOD may also help bacterial pathogens survive against oxidative outbreaks produced by inflammatory cells [47]. As $\operatorname{sod} A$ genes was downregulated in this study, the expression of $\operatorname{sod} M$ in more than half of $S$. aureus was also significantly down-regulated. We suggest that subbacteriostatic concentrations of ZY-214-4 can weaken the antioxidant defense of $S$. aureus by inhibiting sod expression. Insects possess both cellular and humoral immune response pathways, and the related literature reported that the virulence of the strain was weakened by drug action $[48,49]$. In our study, we found 
that ZY-214-4 could reduce the virulence of $S$. aureus in the silkworm. Under the same conditions, the survival time of treated animals was significantly different from that of untreated controls.

The use of mammals for drug development is expensive and ethically problematic [50]. The mechanisms involved in the absorption, distribution, metabolism, and excretion of chemicals are similar in silkworm larvae and mammals $[51,52]$. In this study, we found that ZY214-4 was not cytotoxic within the concentration range tested, and may be beneficial for the treatment of $S$. aureus infection.

\section{Conclusions}

In summary, we found that treatment with a subinhibitory concentration of a new small molecule, ZY-214-4, can reduce the virulence of $S$. aureus by inhibiting pigment production. This study provides a basis for exploring potential drug targets and developing new drugs for the treatment of $S$. aureus infection. However, this study also had some limitations. For example, the level of protection that ZY-214-4 provides against mortality of silkworms is not impressive. Further investigations are needed to clarify the mechanisms underlying how ZY214-4 regulates the expression of $c r t M$ and sod.

\section{Methods}

\section{Bacterial strains}

The strains used in this study are listed in Table 1. The five S. aureus strains-SA21, SA882, SA923, SA2698, and SA2956-were isolated from patients at the First Affiliated Hospital of Wenzhou Medical University. The $S$. aureus isolates and the medical records of the patients were obtained for research purposes with the approval of the Ethics Committee of The First Affiliated Hospital of Wenzhou Medical University. Written informed consent was obtained from all the patients.

\section{Procedure for the synthesis of $\mathrm{C}_{19} \mathrm{H}_{11} \mathrm{BrNO}_{4}$}

ZY-214-4 (Fig. 6) was synthesized by the School of Pharmacy, Wenzhou Medical University [53]. In step 1, chromone 1 ( $0.2 \mathrm{mmol}, 1$ equivalent) and maleimide $2(0.5$ $\mathrm{mmol}, 2.5$ equivalent) were completely dissolved in $2 \mathrm{~mL}$ of 1,2-Dichloroethane (0.1 M DCE) in a 12-mL screwcap tube. In step 2, $\left[\mathrm{Ru}\left(\mathrm{p} \text {-methylbenzyl) } \mathrm{Cl}_{2}\right]_{2} \quad(0.01\right.$ mmol, 0.05 equivalent), $\mathrm{AgNTf}_{2}(0.04 \mathrm{mmol}, 0.2$ equivalent), and AgOAc (0.6 mmol, 3 equivalent) were added to the reaction mixture at room temperature. For step 3 , the mixture was placed on a heating mantle and the temperature was raised to $120^{\circ} \mathrm{C}$ for $0.5 \mathrm{~h}$, with stirring. In step 4 , when the reaction was completed, the entire reaction mixture was directly loaded into a silica gel column, followed by purification with petroleum ether/ EtOAc (step 5), yielding the desired product (product 3) with a yield of $75 \%$. All the reagents used were of analytical grade (Additional Figure 2).

\section{MIC determination}

ZY-214-4 was dissolved in dimethyl sulfoxide (DMSO, BOYUN, SH, China) at a concentration of $20 \mathrm{mg} / \mathrm{mL}$. The broth microdilution method based on CLSI guidelines was used to determine the minimal inhibitory concentration (MIC) [54]. The MIC was defined as the lowest concentration at which no visible bacterial growth was observed. To exclude the influence of the solvent, during the determination, we simultaneously tested the same volume of solvent as a control.

\section{Growth assay}

The $S$. aureus strains were grown in TSB (Becton, Dickinson and Company, NJ, USA) to an optical density (OD) of 0.3 at $600 \mathrm{~nm}$, following which the cultures were aliquoted into five flasks. Different doses of ZY-214-4 were then added to the culture to final concentrations of $4 \mu \mathrm{g} / \mathrm{mL}, 8 \mu \mathrm{g} / \mathrm{mL}$ and $16 \mu \mathrm{g} / \mathrm{mL}$. An Erlenmeyer flask containing only TSB was used as a blank control. All the cultures were incubated at $37^{\circ} \mathrm{C}$ with shaking at 220 $\mathrm{rpm}$. The $\mathrm{OD}_{600}$ value was measured hourly for $24 \mathrm{~h}$. The assay was performed in triplicate.

\section{Pigment extraction}

To evaluate pigment production, the five $S$. aureus strains were inoculated into $10 \mathrm{~mL}$ of TSB with or without ZY-214-4 $(4 \mu \mathrm{g} / \mathrm{mL})$. After $12 \mathrm{~h}$ of incubation, the cultures were centrifuged at 10,000 rpm (enppendorf, F34-6-38) for $10 \mathrm{~min}$. The pellets were washed twice with

Table 1 The minimum inhibitory concentrations (MIC) of ZY-214-4 against five Staphylococcus aureus strains

\begin{tabular}{|c|c|c|c|c|c|}
\hline Strain & $\mathrm{MIC}(\mu \mathrm{g} / \mathrm{mL})$ & Ward & Year & Source & Antimicrobial Agents \\
\hline SA21 & 64 & Digital subtraction angiography (DSA) & 2012 & Tissue & $P G(R) ; O X(R) ; E M(R) ; C C(R) ; L V X(R) ; M X F(R) ; G M(R) ; R I F(R)$ \\
\hline SA882 & 64 & Digestive ward & 2014 & Wound exudate & PG(R);OX(S);EM(S);CC(S);LVX(S); MXF(S);GM(S);RIF(S) \\
\hline SA923 & 64 & Neurology ward & 2014 & Sputum & $\mathrm{PG}(\mathrm{R}) ; \mathrm{OX}(\mathrm{R}) ; \mathrm{EM}(\mathrm{R}) ; \mathrm{CC}(\mathrm{R}) ; \operatorname{LVX}(\mathrm{R}) ; \mathrm{MXF}(\mathrm{R}) ; \mathrm{GM}(\mathrm{S}) ; \mathrm{RIF}(\mathrm{S})$ \\
\hline SA2698 & 256 & Emergency rescue & 2017 & Blood & PG(R);OX(S);EM(S);CC(S);LVX(S); MXF(S);GM(S);RIF(S) \\
\hline SA2956 & 256 & Hemodialysis & 2017 & Blood & $\mathrm{PG}(\mathrm{R}) ; \mathrm{OX}(\mathrm{S}) ; \mathrm{EM}(\mathrm{R}) ; \mathrm{CC}(\mathrm{R}) ; \mathrm{LVX}(\mathrm{R}) ; \mathrm{MXF}(\mathrm{R}) ; \mathrm{GM}(\mathrm{R}) ; \mathrm{RIF}(\mathrm{R})$ \\
\hline
\end{tabular}

PG Penicillin G; OX Oxacillin; EM Erythromycin; CC Clindamycin; LVX Levofloxacin; MXF Moxifloxacin; GM Gentamicin; RIF Rifampicin. R and S denotes drug resistance and drug sensitivity, respectively 
<smiles>O=c1ccoc2ccccc12</smiles>

1<smiles>O=C1C=CC(=O)N1c1ccc(Br)cc1</smiles>

2

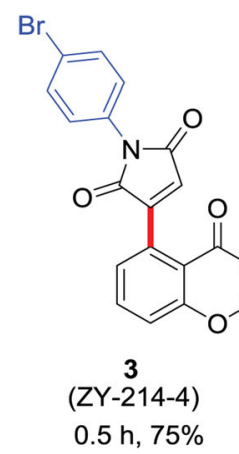

Fig. 6 Procedure for ZY-214-4 synthesis. 1: Chromones; 2: Maleimides; 3: ZY-214-4

PBS, resuspended in $2 \mathrm{~mL}$ of methanol, and placed in an incubator for $24 \mathrm{~h}$ with shaking. The samples were then centrifuged at 10,000 rpm (enppendorf, F-24-6-38) for $10 \mathrm{~min}$, and the OD value was measured at $465 \mathrm{~nm}$. The percent inhibition of pigment production was calculated as follows: pigment inhibition rate $(\%)=\left[\left(\right.\right.$ ControlOD $_{465}$ - TreatedOD 465$) /$ Control $\left.\mathrm{OD}_{465}\right] \times 100[31,55]$.

\section{Oxidant susceptibility assay}

$\mathrm{H}_{2} \mathrm{O}_{2}$ sensitivity assays were performed as previously described [56]. Control and ZY-214-4-treated $(4 \mu \mathrm{g} / \mathrm{mL}) S$. aureus were pelleted by centrifugation at $8000 \mathrm{rpm}$ (enppendorf, F-34-6-38) for $10 \mathrm{~min}$ and resuspended in PBS containing $0.25 \% \mathrm{H}_{2} \mathrm{O}_{2}$ (The chemical reagent $30 \%$ hydrogen peroxide was diluted by aseptic PBS) at $37^{\circ} \mathrm{C}$ for $1 \mathrm{~h}$. The cells were then serially diluted with PBS, spread on TSB agar plates, and incubated at $37^{\circ} \mathrm{C}$ for $12 \mathrm{~h}$. The numbers of viable cells were counted after incubation to determine whether ZY-214-4 affected $S$. aureus susceptibility to $\mathrm{H}_{2} \mathrm{O}_{2}$.

\section{Human whole-blood killing assay}

For the whole-blood killing assay, cultures of each strain treated or not with ZY-214-4 $(4 \mu \mathrm{g} / \mathrm{mL})$ were centrifuged and resuspended in sterile PBS to a final concentration of $1 \times 10^{7} \mathrm{CFU} / \mathrm{mL}$. Whole blood from healthy human volunteers was collected into Vacutainer PT tubes (Becton, Dickinson and Company, NJ, USA). Aliquots $(600 \mu \mathrm{L})$ of whole blood were transferred into $1.5-\mathrm{mL}$ test tubes and mixed with $200 \mu \mathrm{L}$ of bacterial samples to a final concentration of $2.5 \times 10^{6} \mathrm{CFU} / \mathrm{mL}$ as previously described [57]. The tubes were incubated at $37^{\circ} \mathrm{C}$ with shaking $(250 \mathrm{rpm})$ for $1 \mathrm{~h}$, following which dilutions were spread on Colombian blood plates to count the numbers of colonies.

\section{RNA-seq and identification of differentially expressed genes}

Bacteria were cultured for $12 \mathrm{~h}$ in TSB with or without ZY-214-4 $(4 \mu \mathrm{g} / \mathrm{mL})$ and then collected by centrifugation at $12,000 \times g$ for $1 \mathrm{~min}$ at $4{ }^{\circ} \mathrm{C}$. RNA was extracted using the QIAGEN RNeasy Maxi Kit (QIAGEN, BER, Germany) following the manufacturer's instructions. The RNA was sequenced using the Illumina HiSeq $X$ platform with a paired-end read length of $150 \mathrm{bp}$. DEGseq software [58] was used to analyze the effect of ZY214-4 on gene expression. Differences in gene expression were considered significant with $\mid \log 2$ (fold change) $\mid>1$ and $p<0.005$.

\section{Quantitative real-time RT-PCR}

S.aureus was cultured in the medium with and without ZY-214-4 $(4 \mu \mathrm{g} / \mathrm{mL})$. After $12 \mathrm{~h}$, RNA was extracted as described above. The primer pairs used for $\mathrm{qPCR}$ are listed in Table 2. Total RNA was reverse transcribed using a Takara RNA PCR Kit (Takara, Tokyo, Japan). qPCRs were performed in $20-\mu \mathrm{L}$ reaction mixtures using Luna Universal qPCR Master Mix (New England Biolabs, MA, USA). Each test was performed independently in triplicate.

\section{Assessment of the toxicity of ZY-214-4 in the silkworm}

The toxicity of ZY-214-4 against the silkworm was assessed as previously described, with slight modifications [59]. A disposable plastic syringe (Terumo, TY, Japan) was used to inject different concentrations (2$8 \mu \mathrm{g} / \mathrm{mL})$ of ZY-214-4 $(0.05 \mathrm{~mL})$ into the body of

Table 2 Primers used for RT-qPCR

\begin{tabular}{ll}
\hline Primer name & Sequence $\left(\mathbf{5}^{\prime} \mathbf{-} \mathbf{3}^{\prime}\right)$ \\
\hline gyrb-RT-F & ACATTACAGCAGCGTATTAG \\
gyrb-RT-R & CTCATAGTGATAGGAGTCTTCT \\
sodA-RT-F & GACAGACATCATAACACTTA \\
sodA-RT-R & ACTCCCAGAATAATGAATG \\
sodM-RT-F & CTGTACCTTCTACTGCAGCATTTA \\
sodM-RT-R & TTAGAACCACATTITGACAAAGAA \\
crtM-RT-F & CATCGTATGTCTGATGTG \\
crtM -RT-R & GCTGAATTATTCGGATATTG \\
\hline
\end{tabular}


silkworm larvae. The survival rate was measured one day after injection.

\section{The infection of silkworm larvae for the assessment of $S$.} aureus virulence following ZY-214-4 treatment

Staphylococcus aureus strains were cultured on Columbia blood agar plates at $37^{\circ} \mathrm{C}$ overnight. The next day, S. aureus was inoculated into TSB and grown to the logarithmic phase at $37^{\circ} \mathrm{C}$ with shaking $(220 \mathrm{rpm})$. ZY214-4 was added to a final concentration of $4 \mu \mathrm{g} / \mathrm{mL}$. A bacterial solution without ZY-214-4 was used as control. After $12 \mathrm{~h}$, the bacteria were collected by centrifugation at $8000 \mathrm{rpm}$ for $5 \mathrm{~min}$ at $4{ }^{\circ} \mathrm{C}$, washed three times with phosphate-buffer saline (PBS), and diluted to $0.5 \mathrm{McFar}$ land standard at $600 \mathrm{~nm}$. The total colony units were further adjusted to obtain the required dose. For the infection of silkworm larvae, there were 10 larvae in each group, and the weight of each larva is $250 \mathrm{mg}$. Injection was performed as previously described [60] with slight modifications. In brief, a syringe was used to inject $50 \mu \mathrm{L}$ of $S$. aureus into the last left forelimb of each larva. After the injection, the larvae were placed in an incubator at $37^{\circ} \mathrm{C}$, and larval mortality was recorded. Larvae were considered to be dead when they did not respond to touch. Silkworm larvae that were not exposed to ZY214-4 and those injected with phosphate-buffered saline (PBS) were used as controls.

\section{Statistical analysis}

GraphPad Prism 6 (GraphPad Software, version 6.00, https://www.graphpad.com/) was used to analyze the experimental data. A $p$-value $<0.05$ was considered statistically significant. In addition to using log rank test analysis of survival rate of silkworm, all others used oneway analysis of variance.

\section{Supplementary Information}

The online version contains supplementary material available at https://doi. org/10.1186/s12866-021-02113-5

Additional file 1 Figure 1 Growth curves for Staphylococcus aureus strains cultured with ZY-214-4(4 $\mu \mathrm{g} / \mathrm{mL})$. TSB was used as a blank control. Images made by GraphPad Prism 6 (GraphPad Software, version 6.00, https://www.graphpad.com/).

Additional file 2. Figure $2 \mathrm{HPLC}$ of $Z Y-214-4$.

\section{Acknowledgements}

The authors are grateful to the First Affiliated Hospital of Wenzhou Medical University.

\section{Reliability of experimental methods}

All the experimental methods in this article were carried out in accordance with relevant guidelines and regulations. Relevant references and guidelines was marked and quoted in this article.

\section{Authors' contributions}

$J Y, L R, Y Z$, designed of the work and analyzed and interpreted of data for the work. JY, YG, drafted the work and revised it critically for important intellectual content. FY provided approval for publication of the content. $L Z$, BW, ZS, QZ, YX, HZ, XW, participated in the experimental design and data analysis. FY agreed to be accountable for all aspects of the work in ensuring that questions related to the accuracy or integrity of any part of the work are appropriately investigated and resolved. All authors read and approved the final manuscript.

\section{Funding}

This study was supported by grants from the Natural Science Fund of China (81871704) covering the each section of this study, including the design of the study and collection, analysis, and interpretation of the data and manuscript preparation.

\section{Availability of data and materials}

The datasets generated during the current study are available from the corresponding author upon reasonable request. Most of the data is included in this published article.

\section{Ethics approval and consent to participate}

This study was approved by the Ethics Committee of the First Affiliated Hospital of Wenzhou Medical University. Written informed consent was obtained from all the patients. Written informed consent was obtained from all the patients.

\section{Consent for publication}

Not applicable.

\section{Competing interests}

The authors declare they have no competing interests.

\section{Author details}

${ }^{1}$ Department of Laboratory Medicine, The First Affiliated Hospital of Wenzhou Medical University, Wenzhou 325000, China. ${ }^{2}$ Department of Clinical Laboratory, Shanghai Pulmonary Hospital, Tongji University School of Medicine, Shanghai 200082, China. ${ }^{3}$ Nanchang University, Nanchang 330027. China. ${ }^{4}$ School of Pharmaceutical Sciences, Wenzhou Medical University, Wenzhou 325000, China. ${ }^{5}$ Shanghai Key Laboratory of Tuberculosis, Shanghai Pulmonary Hospital, Tongji University School of Medicine, Shanghai 200082, China.

Received: 10 November 2020 Accepted: 2 February 2021

Published online: 27 February 2021

\section{References}

1. Gorwitz RJ, et al. Changes in the prevalence of nasal colonization with Staphylococcus aureus in the United States, 2001-2004. J Infect Dis. 2008; 197(9):1226-34

2. Esposito $\mathrm{S}$, et al. Staphylococcus aureus colonization and risk of surgical site infection in children undergoing clean elective surgery: a cohort study. Medicine (Baltimore). 2018;97(27):e11097.

3. Daum RS. Removing the golden coat of Staphylococcus aureus. N Engl J Med. 2008:359(1):85-7.

4. Oliveira D, Borges A, Simoes M. Staphylococcus aureus Toxins and Their Molecular Activity in Infectious Diseases. Toxins (Basel). 2018;10(6). https://doi. org/10.3390/toxins10060252.

5. Pierce D, Calkins BC, Thornton K. Infectious endocarditis: diagnosis and treatment. Am Fam Physician. 2012;85(10):981-6.

6. Tong SY, et al. Staphylococcus aureus infections: epidemiology, pathophysiology, clinical manifestations, and management. Clin Microbiol Rev. 2015;28(3):603-61.

7. Hu Q, Peng H, Rao X. Molecular events for promotion of Vancomycin resistance in Vancomycin intermediate Staphylococcus aureus. Front Microbiol. 2016:7:1601

8. McGuinness WA, Malachowa N, DeLeo FR. Vancomycin resistance in Staphylococcus aureus. Yale J Biol Med. 2017:90(2):269-81.

9. Cong Y, Yang S, Rao X. Vancomycin resistant Staphylococcus aureus infections: a review of case updating and clinical features. J Adv Res. 2020; 21:169-76.

10. Liu Cl, et al. A cholesterol biosynthesis inhibitor blocks Staphylococcus aureus virulence. Science. 2008;319(5868):1391-4. 
11. Lowy FD. Antimicrobial resistance: the example of Staphylococcus aureus. J Clin Invest. 2003;111(9):1265-73.

12. Cegelski $L$, et al. The biology and future prospects of antivirulence therapies. Nat Rev Microbiol. 2008;6(1):17-27.

13. Hentzer $M$, et al. Inhibition of quorum sensing in Pseudomonas aeruginosa biofilm bacteria by a halogenated furanone compound. Microbiology (Reading). 2002;148(Pt 1):87-102.

14. Bhattacharyya A, et al. Oxidative stress: an essential factor in the pathogenesis of gastrointestinal mucosal diseases. Physiol Rev. 2014;94(2): 329-54.

15. Gaupp R, Ledala N, Somerville GA. Staphylococcal response to oxidative stress. Front Cell Infect Microbiol. 2012;2:33.

16. Treffon J, et al. Importance of superoxide dismutases a and $M$ for protection of Staphylococcus aureus in the oxidative stressful environment of cystic fibrosis airways. Cell Microbiol. 2020;22(5):e13158.

17. Cueno ME, Imai K. Network analytics approach towards identifying potential antivirulence drug targets within the Staphylococcus aureus staphyloxanthin biosynthetic network. Arch Biochem Biophys. 2018;645:816.

18. Liu GY, et al. Staphylococcus aureus golden pigment impairs neutrophil killing and promotes virulence through its antioxidant activity. J Exp Med. 2005;202(2):209-15.

19. Song $Y$, et al. Inhibition of staphyloxanthin virulence factor biosynthesis in Staphylococcus aureus: in vitro, in vivo, and crystallographic results. J Med Chem. 2009:52(13):3869-80.

20. Clauditz A, et al. Staphyloxanthin plays a role in the fitness of Staphylococcus aureus and its ability to cope with oxidative stress. Infect Immun. 2006;74(8):4950-3.

21. Pelz A, et al. Structure and biosynthesis of staphyloxanthin from Staphylococcus aureus. J Biol Chem. 2005;280(37):32493-8.

22. Verma AK, Pratap R. The biological potential of flavones. Nat Prod Rep. 2010; 27(11):1571-93.

23. Gaspar A, et al. Chromone: a valid scaffold in medicinal chemistry. Chem Rev. 2014;114(9):4960-92.

24. Reis J, et al. Chromone as a privileged scaffold in drug discovery: recent advances. J Med Chem. 2017:60(19):7941-57.

25. Martinez A, et al. SAR and 3D-QSAR studies on thiadiazolidinone derivatives: exploration of structural requirements for glycogen synthase kinase 3 inhibitors. J Med Chem. 2005;48(23):7103-12

26. Thoma $\mathrm{G}$, et al. Identification of a potent Janus kinase 3 inhibitor with high selectivity within the Janus kinase family. J Med Chem. 2011;54(1):284-8.

27. Wagner J, et al. Discovery of 3-(1H-indol-3-yl)-4-[2-(4-methylpiperazin-1yl)quinazolin-4-yl]pyrrole-2,5-dione (AEB071), a potent and selective inhibitor of protein kinase C isotypes. J Med Chem. 2009;52(20):6193-6.

28. Palepu A, et al. Hospital utilization and costs in a cohort of injection drug users. CMAJ. 2001;165(4):415-20.

29. Voyich JM, et al. Is Panton-valentine leukocidin the major virulence determinant in community-associated methicillin-resistant Staphylococcus aureus disease? J Infect Dis. 2006;194(12):1761-70.

30. Pannu MK, et al. Role of SigB and Staphyloxanthin in radiation survival of Staphylococcus aureus. Curr Microbiol. 2019;76(1):70-7.

31. Lan $L$, et al. Golden pigment production and virulence gene expression are affected by metabolisms in Staphylococcus aureus. J Bacteriol. 2010;192(12): 3068-77.

32. Xue L, et al. Staphyloxanthin: a potential target for antivirulence therapy Infect Drug Resist. 2019;12:2151-60.

33. $\mathrm{Ni} \mathrm{S}$, et al. Targeting virulence factors as an antimicrobial approach: pigment inhibitors. Med Res Rev. 2020;40(1):293-338.

34. Lang $S$, et al. Identification of a novel antigen from Staphylococcus epidermidis. FEMS Immunol Med Microbiol. 2000;29(3):213-20.

35. Song $Y$, et al. Phosphonosulfonates are potent, selective inhibitors of dehydrosqualene synthase and staphyloxanthin biosynthesis in Staphylococcus aureus. J Med Chem. 2009;52(4):976-88.

36. Vila T, et al. Candida albicans quorum-sensing molecule farnesol modulates staphyloxanthin production and activates the thiol-based oxidative-stress response in staphylococcus aureus. Virulence. 2019;10(1):625-42.

37. Dwyer DJ, Kohanski MA, Collins JJ. Role of reactive oxygen species in antibiotic action and resistance. Curr Opin Microbiol. 2009;12(5):482-9.

38. Liu Q, Mazhar M, Miller LS. Immune and inflammatory Reponses to Staphylococcus aureus skin infections. Curr Dermatol Rep. 2018;7(4):338-49.
39. Ehrnstrom B, et al. TLR8 and complement C5 induce cytokine release and thrombin activation in human whole blood challenged with gram-positive bacteria. J Leukoc Biol. 2020;107(4):673-83.

40. Ellson CD, et al. Neutrophils from p40phox-/- mice exhibit severe defects in NADPH oxidase regulation and oxidant-dependent bacterial killing. J Exp Med. 2006;203(8):1927-37.

41. Painter KL, et al. Infect Immun. 2017:85(12). https://doi.org/10.1128/IAl. 00659-17.

42. Lalaouna D, et al. RsaC sRNA modulates the oxidative stress response of Staphylococcus aureus during manganese starvation. Nucleic Acids Res. 2019:47(18):9871-87.

43. Hussain RM, Abdullah NF, Amom Z. Killing of Staphylococcus aureus by allylpyrocatechol is potentiated by induction of intracellular oxidative stress and inhibition of catalase activity. J Integr Med. 2016;14(6):456-64.

44. Becerra MC, Albesa I. Oxidative stress induced by ciprofloxacin in Staphylococcus aureus. Biochem Biophys Res Commun. 2002;297(4):1003-7.

45. Kehl-Fie TE, et al. Nutrient metal sequestration by calprotectin inhibits bacterial superoxide defense, enhancing neutrophil killing of Staphylococcus aureus. Cell Host Microbe. 2011;10(2):158-64.

46. Karavolos $\mathrm{MH}$, et al. Role and regulation of the superoxide dismutases of Staphylococcus aureus. Microbiology (Reading). 2003;149(Pt 10):2749-58.

47. Das D, Bishayi B. Staphylococcal catalase protects intracellularly survived bacteria by destroying $\mathrm{H} 2 \mathrm{O} 2$ produced by the murine peritoneal macrophages. Microb Pathog. 2009;47(2):57-67.

48. Jander G, Rahme LG, Ausubel FM. Positive correlation between virulence of Pseudomonas aeruginosa mutants in mice and insects. J Bacteriol. 2000; 182(13):3843-5.

49. Peleg AY, et al. Reduced susceptibility to vancomycin influences pathogenicity in Staphylococcus aureus infection. J Infect Dis. 2009;199(4): 532-6.

50. Baumans $V$. Use of animals in experimental research: an ethical dilemma? Gene Ther. 2004;11(Suppl 1):S64-6.

51. Hamamoto $\mathrm{H}$, et al. Quantitative evaluation of the therapeutic effects of antibiotics using silkworms infected with human pathogenic microorganisms. Antimicrob Agents Chemother. 2004;48(3):774-9.

52. Hamamoto $\mathrm{H}$, et al. Effects of molecular mass and hydrophobicity on transport rates through non-specific pathways of the silkworm larva midgut. Int J Antimicrob Agents. 2005;26(1):38-42.

53. Zhou $\mathrm{Y}$, et al. Ruthenium (II)-catalyzed $\mathrm{C}-\mathrm{H}$ activation of Chromones with Maleimides to synthesize Succinimide/Maleimide-containing Chromones. J Org Chem. 2020;85(14):9230-43.

54. Clinical and Laboratory Standard Institute. M100 Performance Standards for Antimicrobial Susceptibility Testing 28th edn. Wayne: Clinical and Laboratory Standards Institute; 2019.

55. Leejae S, Hasap L, Voravuthikunchai SP. Inhibition of staphyloxanthin biosynthesis in Staphylococcus aureus by rhodomyrtone, a novel antibiotic candidate. J Med Microbiol. 2013;62(Pt 3):421-8.

56. Hall JW, et al. Infect Immun. 2017:85(2). https://doi.org/10.1128/IAl.00838-16.

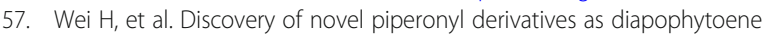
desaturase inhibitors for the treatment of methicillin-, vancomycin- and linezolid-resistant Staphylococcus aureus infections. Eur J Med Chem. 2018; 145:235-51.

58. Wang $L$, et al. DEGseq: an R package for identifying differentially expressed genes from RNA-seq data. Bioinformatics. 2010;26(1):136-8.

59. Hamamoto $\mathrm{H}$, et al. Silkworm as a model animal to evaluate drug candidate toxicity and metabolism. Comp Biochem Physiol C Toxicol Pharmacol. 2009; 149(3):334-9.

60. Desbois AP, Coote PJ. Wax moth larva (galleria mellonella): an in vivo model for assessing the efficacy of antistaphylococcal agents. J Antimicrob Chemother. $2011 ; 66(8): 1785-90$.

\section{Publisher's Note}

Springer Nature remains neutral with regard to jurisdictional claims in published maps and institutional affiliations. 